\title{
Aberrant clinical coding: an underappreciated entity for NHS Trusts, clinicians and coders
}

\author{
AR Medford \\ Consultant Physician and Honorary Senior Clinical Lecturer in Thoracic Medicine E Interventional Pulmonology, North Bristol Lung Centre \\ and University of Bristol, Southmead Hospital, North Bristol NHS Trust, Bristol, UK
}

KEYWORDS: Coding, intervention, tariffs, aberrant coding

DECLARATION OF INTERESTS Dr Medford is the Education Editor for the JRCPE.
Correspondence to ARL Medford,

North Bristol Lung Centre

and University of Bristol,

Southmead Hospital,

Westbury-on-Trym,

Bristol BSIO 5NB, UK

tel. +44 (0) I I 73235284

e-mail

Andrew.Medford@nbt.nhs.uk
Medical records are important not just as a conveyor of clinical information but also as a key method of monitoring and reporting hospital service activity. Each activity is allocated a specific code, which is used for reimbursement purposes. The accuracy of the information in the medical notes is therefore crucial for allocating the correct codes. Under the payment by results $(\mathrm{PbR})$ system in England, hospital Trusts therefore have a financial incentive to ensure efficiency and quality in medical record keeping. Inaccuracies in coding in the UK are well known and have been well-reported by the Audit Commission.' The average Healthcare Resource Group (HRG) error report rate was 8.1\%, with considerable variation (range 1-40\%).' The level of coding errors is cause for concern, given the current economic climate. Diagnosis Related Groups (DRGs) systems have been utilised in North America as a means of classifying hospital 'products' and services for use with prospective payment systems and reimbursement by Medicare for the last three decades. Errors in this system have been reported at a rate of over $20 \%{ }^{2}$ Moreover, 'DRG creep' (changes in hospital record-keeping practices to increase case-mix indexes and reimbursement) occurred in over $60 \%$ of the errors leading to over-reimbursement of services covered by Medicare. ${ }^{3,4}$

\section{THE IMPACT OF ABERRANT CODING}

The financial effects of aberrant coding are most obviously seen in interventional specialties, typically because the tariffs are higher. In the field of interventional pulmonology, for example, the endobronchial ultrasound-guided transbronchial needle aspiration (EBUS-TBNA) tariff is about seven times higher than the conventional bronchoscopy one. The medical thoracoscopy tariff is significantly increased if talc is insufflated at the time of the procedure (the tariff is over three times higher). Aberrant coding rates of between $15 \%$ and nearly $70 \%$ for these two procedures alone in a single centre in the UK have resulted in financial disparities of between $£ 70,000$ and f | 4,000 respectively, per year over the period of study. In otolaryngology, aberrant coding rates of nearly $25 \%$ have resulted in an average revenue loss of $\ell \mid 74$ per patient. ${ }^{7}$ In maxillofacial surgery, an aberrant coding rate of over $50 \%$ for one complex procedure resulted in a financial loss of nearly $£ 78,000$ from only II procedures. ${ }^{8}$ In a study of co-morbidity coding, diabetes mellitus was missed by coders and clinical teams in approximately $25 \%$ and $40 \%$, respectively, of the total cohort. ${ }^{9}$ Although these individual studies have pointed to relatively small disparities, the combined effect of such aberrant coding is likely to be far higher when elective interventional procedures are included (this also does not include inpatient admissions and emergency procedures). In another paper based on orthopaedic activity, it is speculated that $£ 6$ million of a total $£ 30$ million of revenue may be lost due to aberrant coding (including inpatient activity). ${ }^{10}$

\section{DIFFICULTIES WITH CODING SYSTEMS}

Some of these studies also highlight the difficulties with the HRG coding system which has not always kept pace with healthcare innovation, particularly in interventional work." For example, procedures that can only be done in theatre under general anaesthesia generate increased cost and complexity which should be reflected in a higher tariff, but this is not always the case. ${ }^{2}$ In addition, in the field of interventional pulmonology, more complex bronchoscopic techniques such as electrocautery, laser, autofluorescence or thermoplasty are not specifically differentiated from conventional bronchoscopy, despite requiring greater expertise and often more time. Failure of tariffs to reflect innovation also stifles service development by providers. Some progress is being made however, as there are specific separate tariffs for EBUS-TBNA, endobronchial lung volume reduction and cryobiopsy. In cases such as these, local tariff adjustment is sometimes required as an incentive to commissioning bodies. 


\section{IMPROVING CODING}

Clinicians need to engage more closely with coders to improve record keeping and the quality of data collected, to confirm codes and provide clinical leadership in identifying and coding co-morbidities. Clinical coder training and professional development also need to be improved. Finally, coding systems need to be reviewed and updated in line with the rapid progress made in interventional specialities." They also need to be simplified in order to minimise code variations for the same procedure. The 2010/II Audit Commission report emphasised the need for improved senior leadership at Trust level and greater clinical involvement in this process. ${ }^{13}$

A more recent clinical coding quality improvement interventional pulmonology study in the UK confirmed the potential to end aberrant coding for an interventional procedure (with a previously published 15\% aberrant coding rate) through greater clinician engagement with coders. ${ }^{14}$ This was achieved by interventions at no extra cost, using electronic communication between clinicians and coders (a scheduled email containing the hospital identifier for all the interventional procedures was sent to the clinical coder after each list and cross-checked with hospital coding and clinical records). Quality improvement studies in rheumatology and otolaryngology demonstrated that physician interaction with the coders or weekly meetings with them minimised aberrant coding rates to $5-10 \% .^{15,16}$ In terms of inpatient activity, a newly designed burns centre inpatient summary sheet was calculated to have saved $£ 500,000$ of lost income from critical and high dependency care. ${ }^{17}$ Lessons could be learned from this success.

\section{CONCLUSION}

Aberrant coding is ubiquitous and needs to be addressed, particularly in surgical and interventional specialties. Its effects are most pronounced in healthcare systems where $\mathrm{PbR}$ is used. Closer engagement of clinicians with clinical coders is the most important prerequisite to tackling the problem. Several quality improvement studies in different specialties have shown what can be achieved with close collaboration and varying interventions.

\section{REFERENCES}

I Audit Commission. PbR data assurance framework 2007/08. Findings from the first year of the national clinical coding audit programme [Internet] London:Audit Commission; 2008 [cited 2013 March I].Available from: http://archive.audit-commission.gov.uk/auditcommission/site collectiondocuments/AuditCommissionReports/NationalStudies/ PbRsummary.pdf

2 Hsia DC, Krushat WM, Fagan AB et al. Accuracy of diagnostic coding for Medicare patients under the prospective-payment system. N Engl J Med 1988; 318:352-5. http://dx.doi.org//0.1056/ NEJMI98802II3180604

3 Hsia DC.Accuracy of Medicare reimbursement for cardiac arrest JAMA 1990;264:59-62.http://dx.doi.org// 0.100I/jama.1990.034500 I006303|

4 Muldoon JH. Structure and performance of different DRG classification systems for neonatal medicine. Pediatrics 1999; 103:302-18.

5 Medford AR, Agrawal S, Free CM et al. A performance and theoretical cost analysis of endobronchial ultrasound-guided transbronchial needle aspiration in a UK tertiary respiratory centre. QJM 2009; 102:859-64. http://dx.doi.org/ I0.1093/qjmed/hcp I 36

6 Medford AR, Agrawal S, Free CM et al. Retrospective analysis of Healthcare Resource Group coding allocation for local anaesthetic video-assisted 'medical' thoracoscopy in a UK tertiary respiratory centre. QJM 2009; 102:329-33. http://dx.doi.org/I0.1093/qjmed/ hcp0I6

7 Nouraei SA, O'Hanlon S, Butler CR et al. A multidisciplinary audit of clinical coding accuracy in otolaryngology: financial, managerial and clinical governance considerations under payment-by-results. Clin Otolaryngol 2009; 34:43-5I. http://dx.doi.org/I0.IIII/ i. I749-4486.2008.01863.x

8 Moar KK, Rogers SN. Impact of coding errors on departmental income: an audit of coding of microvascular free tissue transfer cases using OPCS-4 in UK. Brit J Oral Maxillofac Surg 2012; 50:857. http://dx.doi.org/10.10I6/j.bjoms.20II.0I.005

9 Daultrey H, Gooday C, Dhatariya K. Increased length of inpatient stay and poor clinical coding: audit of patients with diabetes. JRSM Short Rep 20 I I;2:83.http://dx.doi.org/ I 0. I258/shorts.20 I I.0 I I I 00

10 Jameson S, Reed MR. Payment by results and coding practice in the National Health Service. The importance for orthopaedic surgeons. J Bone Joint Surg Br 2007; 89:1427-30. http://dx.doi. org/I0.1302/030I-620X.89BII.19609

II Medford AR. Endobronchial ultrasound-transbronchial needle aspiration and lung cancer.J R Coll Physicians Edinb 2009; 39:91.

12 Townley WA, Urbanska C, Dunn RL et al. Costs and coding-freeflap reconstruction in lower-limb trauma. Injury 20I I; 42:38I-4. http://dx.doi.org/I0.10I6/j.injury.2010.10.006

13 Audit Commission. Improving coding, costing and commissioning. Annual report on the payment by results data assurance programme 2010/II [Internet]. London:Audit Commission; 20II [cited 2013 March I].Available from: http://www.audit-commission.gov.uk/wpcontent/uploads/2013/02/pbrannualreport20I I.pdf

14 Pillai A, Medford AR. Greater physician involvement improves coding outcomes in EBUS-TBNA procedures. Respiration 2013. Forthcoming. http://dx.doi.org//0.I I59/000346574

I5 Nallasivan S, Gillott T, Kamath S et al. Physician involvement enhances coding accuracy to ensure national standards: an initiative to improve awareness among new junior trainees. J R Coll Physicians Edinb 20II; 4I:106-8. http://dx.doi.org/10.4997/ IRCPE.20II.220

16 Carr ER, Pillai A. Re: A multidisciplinary audit of clinical coding accuracy in otolaryngology: financial, managerial and clinical governance considerations under payment-by-results. Clin Otolaryngol 2009; 34:259-60. http://dx.doi.org/I0.I I I I/j. I749-4486.2009.0I933.x

17 Wallis KL, Malic CC, Littlewood SL et al. Surviving "Payment by Results": a simple method of improving clinical coding in burn specialised services in the United Kingdom. Burns 2009; 35:232-6. http://dx.doi.org/I0.10I6/j.burns.2008.06.008 